\title{
ЛОНГИТЮДНОЕ ИССЛЕДОВАНИЕ ОТНОШЕНИЯ РОССИЙСКИХ ГРАЖДАН К ИНСТИТУТАМ СТРАХОВАНИЯ И ИНВЕСТИРОВАНИЯ
}

\author{
O.В. Медяник \\ Санкт-Петербургский государственный университет, г. Санкт-Петербург, Россия
}

\begin{abstract}
Исследовано отношение к страховой отрасли как к неотъемлемой части современного российского общества и экономики, рассматриваемой в качестве важнейшего способа защиты частных и юридических лиц от критических событий, осуществляемой благодаря принятию на себя страховых рисков, аккумулированию их, контролю и частичной передаче в перестрахование и на финансовые рынки.

Показано, что страховая система создала условия для экономического равновесия, повышения уровня социальной защищенности граждан, что в целом способствует привлечению в экономику инвестиций. Рассмотрены частное инвестирование и страхование как источник «долгих» денег, аккумулированных для обеспечения страховых выплат крупных активов. Отмечен тренд долгосрочного инвестирования, учитывающий продолжительный временной период наступления убытков. Обосновано мнение о том, что в отличие от многих других экономических институтов, страховые компании являются залогом стабильности финансовой системы. При этом показано, что исключение составляют организации, принимающие на себя серьезные финансовые риски в результате андеррайтинга.

Представлены результаты лонгитюдного метода наблюдения за страховым и инвестиционным поведением страхователей, проживающих в г. Санкт-Петербурге на протяжении тринадцати лет наблюдения. Выборка представлена разнополыми и разновозрастными потребителями страховых услуг с различным уровнем дохода. В результате пролонгированного наблюдения определены особенности генезиса отношения граждан к государственной политике страхования и сформирована типология страхователей, основанная на совокупности психологических характеристик экономического поведения граждан, в частности выгоды (пользы), рациональности, доверии, тревожности и отношении к риску.

Ключевые слова: страховое поведение, страховые риски, экономическая безопасность личности, типология страхователя.
\end{abstract}

\section{Введение}

В современной ситуации страхование и инвестирование являются важнейшей частью стратегического планирования, позволяющего прогнозировать финансовое поведение граждан и определяющего экономику России в ближайший период и в дальней перспективе.

Опыт стран с развитой рыночной экономикой показывает, что в условиях реформирования экономики и в кризисных ситуациях роль государства возрастает, а в период стабильности и оживления экономики - снижается, но государственное влияние никогда не исчерпывается.

В период существования СССР в обществе культивировались патерналистские настроения, декларировалась государственная защита вкладов и страхования граждан страны. На деле такая защита осуществлялась не во всех случаях и не всегда в полном объеме, но при этом у граждан сохранялась иллюзия защищенности. Государственный контроль за минимизацией ущерба от стихийных явлений, производственных аварий и травматизма в сознании граждан превращал личное страхование в абсолютно необязательную, второстепенную сферу. С распадом СССР и переходом от плановой экономики к рыночной начинает повышаться и роль страхования.

В западных странах, в отличие от России, институт страхования давно имеет массовый характер и рассматривается как важнейший фактор, гарантирующий защиту личного имущества граждан. Например, в Германии, Израиле, США - мировых лидерах в области здравоохранения - государственные программы обязывают каждого гражданина иметь медицинскую страховку. Кроме того, стратегии медицинского страхования являются важным пунктом избирательных программ многих западных политических лидеров. Так, нынешний президент США Д. Трамп в самом 
начале своего президентского срока отменил реформу здравоохранения Obama care и программу государственного субсидирования Medicaid, с которой пришел к власти его предшественник Б. Обама (Акерлоф, Шиллер, 2014).

В отличие от этого, программа добровольного медицинского страхования, которая обеспечила бы привлечение средств в отечественную медицину, в нашей стране не получила надлежащего развития. В России роль страховщика первой инстанции выполняет государство, а не частные компании, как в западных странах. При этом, к сожалению, российские страховщики до сих пор не готовы перенять значительную часть рисков, которые в настоящий момент покрываются средствами государственного бюджета (Рейтинговое агентство RAEX, 1998). В отличие от этого, например, в Германии доля страховых услуг, предоставляемых физическим лицам, составляет $87 \%$ всего страхового рынка. Столь высокий показатель достигнут благодаря целенаправленной государственной политике.

Очевидно, что российское государство в период экономического «взросления» должно уделять больше внимания человеку как субъекту инвестиционной деятельности (Баева, 2007). Именно частные инвестиции граждан в значительной мере «запускают» экономику государства. Кроме того, с увеличением числа рисков в жизни граждан обоснованно увеличивается их интерес к страховым институтам вообще (Дейнека, 2008).

Актуальность этого вопроса велика, поскольку на макроэкономическом уровне экономика «пронизывается» человеческим фактором, который воплощается в воле к ответственной оценке последствий принятия экономико-политических решений (Дейнека, 2008).

Сегодня в России существуют объективные предпосылки для развития института страхования.

Во-первых, в результате экономического кризиса уменьшились финансовые возможности населения и одновременно возникла необходимость дополнительных расходов, например, на медицинскую помощь или обучение детей; снизились социальные гарантии по финансовой защите нетрудоспособных граждан (Дейнека, 2010).

Во-вторых, российские граждане все чаще стали пользоваться услугами кредитова- ния, обязательным условием которого является предоставление финансовых гарантий, одной из которых служит договор страхования жизни (Дейнека, 2009б).

Нельзя не отметить позитивные изменения, появившиеся на российском страховом рынке: страховые компании научились оперативно реагировать на нужды потребителя страховых услуг, внедряя как хорошо зарекомендовавшие себя предложения, так и инновационные страховые продукты. Безусловным плюсом стал отказ практически всех серьезных страховых компаний от использования «серых» и «псевдо» схем и упор на развитие традиционных способов страхования (Русецкая и др., 2010).

Так, интенсивное развитие банковского сектора и программы автокредитования с 2000-х годов обусловило резкий скачок продаж новых автотранспортных средств. Именно банки дали первый толчок развитию рынка добровольного автострахования в России. При этом всю информацию о страховых услугах и инвестиционных программах потребитель получал от страховых посредников, которые, как правило, не имели в то время надлежащей профессиональной подготовки, поскольку профильная специальность «страховое дело» в отечественных вузах в то время не изучалась.

Однако интерес самих страховых агентов, как правило, сводился в основном к реализации страхового полиса, независимо от надежности компании, и получению мгновенной прибыли (Найт, 2003). Например, в 20032010 гг. большинство организаций, активно позиционировавших себя на этом рынке страховых услуг в г. Санкт-Петербурге, находились в состоянии жесткой конкуренции друг с другом в сфере автострахования ${ }^{1}$. Полисы этих компаний пользовались спросом у потребителей, что вызвало их стремление использовать в своей деятельности стратегию «Калиф на час». Подобные организации не планировали заниматься страхованием всерь-

1 Такой вывод обосновывается результатами нашего исследования, включавшего в себя изучение различных аспектов привлечения потребителей услуг автострахования, использовавшегося некоторыми известными в то время страховыми компаниями, например, ООО «Северо-Западная страховая компания», ЗАО «Страховая группа «УралСиб», ООО «Русский мир», ОАО «Ростра», ООО «Прогресс-Нева» (прим. автора). 


\section{Общая психология, психология личности, история психологии}

ез, делая ставку только на массовую и быструю распродажу страховых полисов. Непродуманная тарифная политика и непрофессиональное управление страховыми рисками обрушили бюджеты этих компаний. Они ушли с рынка, оставив после себя долги перед страхователями и негативное отношение к страхованию в целом. Конечно, при грамотном государственном регулировании и более полной защите интересов потребителей отношение к страхованию и инвестированию сегодня было бы более благоприятным. Но государственная политика в области страхования еще и сегодня определяется подходом «спасение утопающих - дело рук самих утопающих».

С 2010 года состояние страхового рынка в основном определялось возможностями появления на нем некоторой доли дохода отдельно взятой семьи, что предусматривало формирование курса на оплату страхового полиса в условиях кризисного состояния экономики и с учетом бюджета каждой российской семьи соответственно (Карпусь, Зайнуллин, 2012). В условиях сильной дифференциации и расслоения общества по уровню доходов значительное число граждан страны не имело реальных возможностей пользоваться страховыми услугами из-за невозможности оплачивать их стоимость.

Кроме того, страхователи со стажем нередко руководствовались личностным фактором, следуя за предложениями страховых агентов, которые при поиске выгодных страховых программ чаще опирались на интуицию, часто переходя из одной компании в другую (часто конкурирующую), иногда без учета уровня ее известности либо деловой репутации на страховом рынке.

Этот принцип стал для российского страхователя и инвестора привычным, не предполагавшим критического осмысления. Наибольшая сложность возникала у тех граждан, которые впервые решили заключить договор страхования. Оказавшись в полном неведении, люди прибегали к интернет-источникам для поиска страховой программы. Как правило, таким потребителям удавалось найти две-три «выгодных» компании, предлагавших самую низкую стоимость страхового полиса, но не информировавших об отсутствии своего филиала или представительства в месте проживания страхователя, что существенно осложняло процесс принятия решений и получения выплат по страховым случаям (Кармин, 2004).
Тем не менее, несмотря на наличие потребительского спроса и присутствие на отечественном рынке крупных страховых организаций, развивающих классические виды страхования и способных в полном объеме удовлетворить нужды населения, на данный момент приходится констатировать спад потребительской активности в секторе реального страхования жизни (Залтман, 2006).

Сегодня в России не используется в полной мере огромный потенциал, заложенный в сфере страхования жизни; социальное значение этого вида страхования, его действенность в повышении уровня социальной защищенности граждан недооцениваются на государственном уровне. Отсутствие стратегической и тактической государственных программ развития страхования жизни делает невозможным переход российского страхового рынка на качественно новый этап, при котором институт страхования становится одним из основополагающих секторов экономики (Рейтинговое агентство RAEX, 1998).

Весь путь развития страхования и сама суть частного инвестирования указывают на взаимосвязь экономического и психологического факторов, поэтому задачей экономических психологов, социологов, экономистов должна стать адаптация и совершенствование этой отрасли для граждан (Страхование. Современный курс..., 2006).

Цель исследования - лонгитюдное психологическое исследование методом наблюдения за отношением граждан к государственной политике страхования.

Предметом исследования явились психологические характеристики отражения содержания страховой и инвестиционной политики государства в сознании граждан.

Объектом исследования стали потребители страховых услуг - клиенты страховых компаний г. Санкт-Петербурга, с различными социально-демографическими характеристиками (возраст, уровень дохода и образование).

Гипотезы исследования:

- гипотеза № 1: для любого гражданина потребность в страховании, и следовательно, в экономической безопасности, рассматривается прежде всего как позитивная психологическая категория, основанная на предположении о том, что возможность избежать страховых рисков выше, чем вероятность их наступления. 
- гипотеза № 2: вероятно, у российских граждан еще преобладают иждивенческие и патерналистские настроения, как последствия страховой политики советского периода, когда государство всю инициативу по защите граждан по всем страховым рискам брало на себя.

Задачи, которые предстояло решить в ходе исследования:

1. Обоснование актуальности и новизны проблемы отношения граждан к государственной политике, стимулирующей инвестиционное поведение гражданина в России, основанное на оценке внутренних и внешних экономических рисков, рассматриваемые в рамках политической и экономической психологии как научной дисциплины;

2. Адаптация и использование качественного лонгитюдного метода наблюдения применительно к исследованию отношения граждан к государственной политике страхования и связанного с ним поведения клиентов страховых компаний на рынке страховых услуг.

\section{1. Методы эмпирического исследования}

Дизайн, методы и выборка участников исследования. Исследование носило лонгитюдный характер и длилось четырнадцать лет, в период с 2008 г. по 2017 г. Сочетались методы наблюдения, опроса, неструктурированного интервью в различных по численности и своим характеристикам группах клиентов различных страховых компаний, оказывающих различные страховые услуги жителям г. Санкт-Петербурга. Временной точкой организации исследования являлся момент заключения договора (ежегодного продления страхового полиса) на основании предложений страховых компаний, опосредованных деятельностью страховых посредников. При проведении исследования оценивалось отношение граждан к страхованию как финансовому институту в целом, мера лояльности к той или иной страховой компании и предлагаемым ею страховым продуктам, выявлялись как позитивные, так и негативные мнения о работе страховых структур. Проводилось наблюдение за поведением потребителей как непосредственно в момент исследования, так и в течение предшествующего годового периода, проводилось интервьюирование с возможностью уточнения характера получаемой информации в объеме, достаточном для анализа деятельности страховых компаний, качества страховых продуктов, особенностей отношения граждан к ним и характеристики поведения потребителей страховых услуг на страховом рынке.

Всего выборку исследования составили 3304 клиента разных страховых компаний г. Санкт-Петербурга. Основную группу составили 1250 человек, ежегодно продлевавших ранее заключенные ими договоры страхования. Углубленное исследование проводилось в выборке 53 клиентов страховых компаний г. Санкт-Петербурга, в том числе 31 женщина и 22 мужчины в возрасте от 25 до 45 лет с уровнем дохода, субъективно оцениваемым как «средний» либо «высокий».

Такого рода организация и методы исследования позволили получить валидные данные о процессе социализации страхователей, о некоторых психологических характеристиках, обусловленных наличием определенных внутренних и внешних экономических рисков. Кроме того, на основании проявления ряда ранее выделенных (Дейнека, 2009а) психологических характеристик страхового и инвестиционного поведения граждан (выгода [польза], рациональность, доверие, тревожность и отношение к риску) была выполнена кластеризация страхователей по типологически однородным типам (группам), характеризующимся относительно однородными признаками, определяемыми социально-экономическими и психологическими характеристиками их поведения на рынке страховых услуг.

\section{2. Результаты эмпирического исследования}

Типология страхователей (потребителей предлагаемых страховими компаніями услуг и продуктов) представлена следующим образом.

Первый тип страхователей (15\% выборки), номинированный как «экономический» («рациональный»), представлен гражданами, которые ежегодно на протяжении долгого времени покупают страховой полис и своими действиями демонстрируют наличие у них прагматической позиции. Они обдуманно заботятся о сохранении своего имущества, приобретают страховые полисы с полным страховым покрытием и делают это на весь период до окончательной продажи своего имущества. Большинство из них не надеется на помощь государства при наступлении страхово- 


\section{Общая психология, психология личности, история психологии}

го случая, но доверяет профессионаламэкономистам и страховым консультантам. Поведение страховых партнеров регламентируется договором, который устанавливает обязательные для них нормы и правила действий. Выбор страхового продукта такими страхователями зависит от стоимости и набора необходимых условий для «спокойной жизни» их собственности. Интересно, что установка получить максимальную экономическую выгоду далеко не всегда оказывается разумной из-за чрезмерной расчетливости. В целом таких потребителей страховых услуг определяют как «экономические люди» (Кармин, 2004).

Второй mun - самый многочисленный (63 \% выборки), представлен «доверчивыми» потребителями страховых услуг. Экономическое мышление этих граждан во многом зависит от психологических факторов: красоты упаковки, в которую вложен полис; яркости рекламы той или иной страховой компании; профессиональных качеств продавца (например, от формы построения страховым агентом разговора, при которой клиент вынужден постоянно с ним соглашаться, а последовательные утвердительные ответы снижают барьер критического восприятия информации клиентом, что создает предпосылки для манипуляции при продаже своей страховой услуги) и т. п. Главная проблема таких граждан состоит в недостатке их финансовой грамотности. Как следствие, они с легкость реагируют на распродажи или скидки, особо не вникая в условия и рейтинги страховых компаний (Дейнека, 1999).

Tретий тип - «тревожный» или «ситуативный» отмечается у $10 \%$ принявших участие в исследовании. Такие страхователи при принятии экономических решений опираются на интуицию, а их экономическое поведение носит непостоянный характер. Опора на интуицию приводит к быстрому принятию решения и освобождает от необходимости логически обосновывать свое поведение. Ситуативная мотивация возникает у них внезапно и, как правило, под влиянием случайных обстоятельств: например информация знакомых о квартирной краже у незастрахованных жильцов или об угоне незастрахованного автомобиля, либо даже редко возникающие обстоятельства, например, прошедший ураган. При этом такая мотивация может исчезнуть так же быстро, как и появилась. Такой клиент может вести долгий и обстоятельный разговор об условиях страхования, но на следующий день бесследно пропасть. Кроме того, таких клиентов очень интересует информация, которую предоставляет государство в продвижении экономических программ страхования и инвестирования. Страхование и инвестирование для этого типа потребителей является своего рода психологической защитой от неизвестности, от страха потери имущества. В психологическом плане важно отметить, что такие граждане порой являются «легкой добычей» страховых посредников, особенно если последние применяют незатейливые схемы запугивания, приводящие потребителя в состояние эмоционального возбуждения, заставляя его торопится, плохо просчитывать свои риски и, в итоге, выбирать невыгодную для себя программу страхования. Можно считать, что срабатывает «потребительский вариант» закона Йеркса - Додсона, прикладная суть которого состоит в том, что при сильной мотивации и сильном желании приобрести страховой продукт, человек «закрывает глаза» на его недостатки (Кармин, 2004).

Четвертый тип, получивший название «рисковый» («нерациональный») отмечается у $12 \%$ респондентов. Такие граждане не доверяют ни государству, ни страховым компаниям и намеренно идут на экономический риск. Их знакомство со страховыми продуктами носит в основном разовый характер и порождается только конкретными обстоятельствами, например, при необходимости застраховать свой автомобиль, жизнь или квартиру при заявке на получение кредита. Как правило, эти люди рассчитывают «на авось», действуют наобум, их страховая стратегия не исключает надежды на страховку, оформленную «задним числом». Такого рода экономические ошибки во многом обусловлены личным и экономическим консерватизмом («никогда не страховался - и дальше не буду испытывать судьбу»), эгоцентризмом (проявляющимся чрезмерным доверием личному опыту и уверенностью, что ничего не случится), следованием так называемому «эффекту Ирвина», проявляющегося переоценкой вероятности наступления «хороших событий» и недооценкой возможности наступления «плохих» (Кармин, 2004). Представители такого типа верят в свою способность влиять на ход событий, которые, по определению, никак от них не зависят. 


\section{3. Обсуждение результатов} эмпирического исследования

Результаты выполненного исследования позволяют предполагать, что для любого человека потребность в страховании, и, следовательно, экономической безопасности, безусловно, представляет собой прежде всего психологическую категорию, связанную с оценочной и прогностической функцией психики (например, при принятии решения на основе вывода о преобладании возможности избегания страховых рисков над вероятностью их наступления). Поэтому зачастую выбор российских граждан на рынке страховых услуг носил и носит ситуативный характер, имеет место расчет на счастливый случай или даже «на авось». Тем не менее у потребителей страховых услуг достаточно отчетливо выражается и понимание того, что государство не может гарантировать бесплатную защиту, кроме отдельных чрезвычайных ситуаций (Найт, 2003).

Получила свое подтверждение версия о том, что деструктивная и непрофессиональная работа представителей страхового и инвестиционного рынка в предшествующий период подорвала доверие потребителей в гарантированную защиту, несмотря на то, что у респондентов существует понимание того, что оплата «спокойствия» за свое имущество и жизнь в будущем лежит в основе страхования. При этом свое персональное недоверие к страховым институтам гражданин, в свою очередь, проецирует на существующее в обществе недоверие к экономической политике государства. Кроме того, установлено, что даже наличие разветвленной сети отечественных страховых компаний не исключает возможность и надежду небольшого числа потребителей страховых услуг на страхование свои рисков и на хранение своих накоплений за рубежом (Ильин, 2007).

\section{Заключение}

Несомненно, предложенная типология нуждается в более развернутой эмпирической проверке и подтверждению методами статистического анализа и математического моделирования. В настоящее время проводится корреляционное и многофакторное исследование потребителей страхового рынка с помощью оригинального авторского опросника «Отношение граждан к страхованию и инвестированию».
Таким образом, психологическое исследование позволило не только выявить изменения в экономическом сознании участников рынка, но и зафиксировать типологические различия страхователей. В условиях развития рыночной экономики самым серьезным риском для государства, способным обрушить всю макроэкономическую систему, является отказ населения от активного экономического поведения. Стабильность - это обязательное условие экономической безопасности государства, а финансовая неопределённость определяет появление серьезного психологического состояния индивида, обеспокоенного состоянием и динамикой собственных сбережений и трат, и, что важнее всего, оценкой прибыли, которую могут принести потенциальные вложения личных средств в различные сберегательные, инвестиционные или страховые институты. Необходимым условием активности граждан в области финансового поведения является ощущение финансовой определенности, которое в поведенческой экономике определяется как потребительское доверие. Высокий уровень этого показателя позволяет человеку оптимистично смотреть в будущее, обосновывает возможность траты больших денежных средств, получения в банках потребительских и иных кредитов, и, в частности, не экономить на страховых услугах. Соответственно, пессимистично настроенные граждане меньше доверяют разнообразным финансовым институтам, в том числе банкам и страховым компаниям.

Полученные нами данные позволяют считать, что страховая система должна рассматриваться как на государственном уровне, так и на уровне конкретных участников - страховщиков и страхователей.

В первом случае необходимость страхования расценивается как экономическая категория. Чрезвычайные ситуации (масштабные стихийные бедствия, техногенные катаклизмы и крупные производственные аварии и т. п.) сегодня по ряду объективных и субъективных факторов представляются явлениями неизбежными и носящими большой ущерб государственному бюджету и личному благополучию граждан. Поэтому для нормального фукционирования и развития государства и финансовых институтов необходимо создание соответствующих страховых резервов. При этом на формирование государственной политики в отношении страхования во многом оказывает 


\section{Общая психология, психология личности, история психологии}

влияние психология представителей законодательной и исполнительной власти, понимание либо недооценка ими важности создания условий для развития отрасли. Эта политика, в свою очередь, формирует страховое и инвестиционное поведение населения.

Как следствие, требуется разработать стройную и внятную систему экономической пропаганды и информирования граждан о необходимости обеспечения долгосрочной финансовой защиты, препятствующей формированию ощущения неопределенности. Новые реалии требуют изменения психологии в отношении страхования на всех уровнях.

\section{Лumepamypa}

1. Акерлоф, Д. Spiritus Animalis, или Как человеческая психология управляет экономикой $u$ почему это важно для мирового капитализма / Д. Акерлоф, Р. Шиллер. - М.: Юнайтед Пресс, 2014.

2. Баева, И.А. Психологическая безопасность среды: условие активной работы и направление научных исследований / И.А. Баева // Вестник практической психологии образования. - 2007. - № 4. - C. 47-50.

3. Дейнека, О.С. Экономическая психология: сочиально-политические проблемь / О.С. Дейнека. - СПб.: СПбГУ, 1999.

4. Дейнека, О.С. Социальные регуляторы как факторы реализации экономической власти и политики / О.С. Дейнека // Психология власти: материаль 2-й междунар. науч. конф. - СПб.: СПбГУ, 2008. - C. 37-41.

5. Дейнека, О.С. Методология экономикополитических исследований на кафедре политической психологии СПбГУ / О.С. Дейнека // Теория и практика российской политической психологии. СПб.: Изд-во С.-Петерб. ун-та, 2009а. - С. 174177.
6. Дейнека, О.С. Образ экономической политики в период кризиса / О.С. Дейнека // Психологические инновачии в экономике и финансах: Материаль международной научно-практической конференичии. - М.: ФА, Ларк ЛТД, 2009б. - С. 36-39.

7. Дейнека, О.С. Динамика образа экономической политики в период кризиса / О.С. Дейнека // Актуальные проблемы современной политической психологии. - М.: РИОР, 2010. - С. 198-204.

8. Залтман, Дж. Как мыслят потребители. То, о чем не скажет потребитель, то, чего не знает ваш конкурент / Дж. Залтман. - СПб.: Прайм-Еврознак, 2006.

9. Ильин, В.А. Использование психосочиального подхода для изучения соичальнопсихологических процессов в современном обществе / В.А. Ильин // Вопросы психологии. - 2007. № 2. - C. 109-123.

10. Кармин, А.С. Психология рекламы / А.С. Кармин // Психология и культура. - СПб.: Изд. ДНК, 2004. - С. 318-411.

11. Карпусь, Н.П. Саморегулирование как способ минимизащии угроз экономической безопасности / Н.П. Карпусь, С.Б. Зайнуллин // Наџиональные интересы: приоритеть и безопасность. - 2012. - № 37(178). - C. 40-44.

12. Найт, Ф. Риск, неопределенность и прибыль / Ф. Найт. - М.: Дело, 2003.

13. Рейтинговое агентство RAEX («Эксперт PA»): рейтинги, исследования, обзоры, конференųuи. 1998. - https://raexpert.ru/researches/ insurancel handbook_1998/part_10 (дата обращчения: 28.03.2018).

14. Русецкая, Э.А. Страхование как механизм обеспечения экономической безопасности России / Э.А. Русеикая, В.А. Арустамова, Е.В. Аксененко, М.Г. Русеикий // Нацииональные интересы: приоритеты и безопасность. - 2010. - № 15(72). C. 34-43.

15. Страхование. Современный курс: учебник / под ред. Е.В. Коломина. - М.: Финансы и статистика, 2006.

Медяник Ольга Викторовна, ассистент кафедры политической психологии, Санкт-Петербургский государственный университет (Санкт-Петербург), Российская Федерация, medjanik-olga@lenta.ru

Поступила в редакцию 22 февраля 2018 z. 
DOI: $10.14529 / p s y 180203$

\title{
LONGITUDINAL STUDY OF ATTITUDE OF RUSSIAN CITIZENS TOWARD INSURANCE AND INVESTMENT INSTITUTES
}

\author{
O.V. Medyanik, medjanik-olga@lenta.ru \\ Saint Petersburg State University, St. Petersburg, Russian Federation
}

Insurance sphere is an integral part of modern Russian society and economy. Insurance became the important way of protection of legal entities and individuals from critical events thanks to assumption of covered risks, their accumulating, control and partial transferring to reinsurance and to financial markets.

Insurance system has created conditions for economical balance, increase of citizens' social security level and it as well promotes attraction of investments to economy. Private insurance and investment - it is the source of "long" money, when for provision of insurance payments the major assets are accumulated. Insurance underwriters are ready to realize the long-term investments taking into consideration the sustainable period of loss occurrence. In such a way, in contradistinction from many other economic institutes, insurance companies are the guarantors of financial system stability (companies, which assume serious financial risks in the result of underwriting, are the exception).

There are presented the results of longitudinal method of observation over insurance and investment behavior of Saint Petersburg's insurants during the last thirteen years. Sampling consisted of both male and female consumers of insurance services of different age and income level. Besides the study of genesis of citizen's attitude towards state insurance policy, the prolonged observation allowed to define the typology of insurants. The following psychological characteristics of economic behavior of citizens served as criteria for dividing insurants into one or another type: profit (advantage), rationality, trust, anxiety and attitude to risk.

Keywords: insurance behavior, insurance risks, economical safety of person, typology of an insurant.

References

1. Akerlof D., Shiller R. Spiritus Animalis, ili Kak chelovecheskaya psikhologiya upravlyaet ekonomikoy $i$ pochemu eto vazhno dlya mirovogo kapitalizma. [Spiritus Animalis, or How Human Psychology Manages the Economy and Why it is Important for World Capitalism]. Moscow, Yunayted Press Publ., 2014.

2. Baeva I.A. Psikhologicheskaya bezopasnost' sredy: uslovie aktivnoy raboty i napravlenie nauchnykh issledovaniy [Psychological Security of the Environment: the Condition of Active Work and the Direction of Scientific Research]. Vestnik prakticheskoy psikhologii obrazovaniya [Bulletin of Practical Psychology of Education], 2007, no. 4, pp. 47-50.

3. Deyneka O.S. Ekonomicheskaya psikhologiya: sotsial'no-politicheskie problem [Economic Psychology: Socio-political Problems]. St. Petersburg, SPbGU Publ., 1999.

4. Deyneka O.S. [Social Regulators as Factors of Realization of the Economic Power and a Policy]. Psikhologiya vlasti [Psychology of Power]. St. Petersburg, SPbGU Publ., 2008, pp. 37-41. (in Russ.)

5. Deyneka O.S. [Methodology of Economic and Political Studies at the Department of Political Psychology of St. Petersburg State University]. Teoriya i praktika rossiyskoy politicheskoy psikhologii [Theory and Practice of Russian Political Psychology]. St. Petersburg, St. Petersburg University Publ., 2009a, pp. 174-177. (in Russ.)

6. Deyneka O.S. [The Image of Economic Policy During the Crisis]. Psikhologicheskie innovatsii v ekonomike i finansakh [Psychological Innovations in Economics and Finance]. Moscow, FA, Lark LTD, 2009b, pp. 3639. (in Russ.)

7. Deyneka O.S. [Dynamics of the Image of Economic Policy in Times of Crisis]. Aktual'nye problemy sovremennoy politicheskoy psikhologii [Actual Problems of Modern Political Psychology]. Moscow, RIOR Publ., 2010, pp. 198-204. (in Russ.)

8. Zaltman Dzh. Kak myslyat potrebiteli. To, o chem ne skazhet potrebitel', to, chego ne znaet vash konkurent [How do Consumers Think. What the Consumer will not Say, what Your Competitor does not Know]. St. Petersburg, Praym-Evroznak Publ., 2006.

9. Il'in V.A. [The Use of the Psychosocial Approach for the Study of Socio-psychological Processes in Modern Society]. Voprosy psikhologii [Questions of Psychology], 2007, no. 2, pp. 109-123. (in Russ.) 


\section{Общая психология, психология личности, история психологии}

10. Karmin A.S. [Psychology of Advertising]. Psikhologiya $i$ kul'tura [Psychology and Culture]. St. Petersburg, DNK Publ., 2004, pp. 318-411. (in Russ.)

11. Karpus' N.P., Zaynullin S.B. [Self-regulation as a Way of Minimizing Threats to Economic Security]. Natsional'nye interesy: prioritety i bezopasnost' [National Interests: Priorities and Security], 2012, no. 37(178), pp. 40-44. (in Russ.)

12. Nayt F. Risk, neopredelennost' i pribyl' [Risk, Uncertainty and Profit]. Moscow, Delo Publ., 2003.

13. Reytingovoe agentstvo RAEX («Ekspert RA»): reytingi, issledovaniya, obzory, konferentsii [RAEX Rating Agency ("Expert RA"): Ratings, Studies, Reviews, Conferences]. 1998. Available at: https://raexpert.ru/researches/insurance/handbook_1998/part_10 (accessed: 28.03.2018).

14. Rusetskaya E.A., Arustamova V.A., Aksenenko E.V., Rusetskiy M.G. Strakhovanie kak mekhanizm obespecheniya ekonomicheskoy bezopasnosti Rossii [The Image of Economic Policy in Times of Crisis]. Natsional'nye interesy: prioritety i bezopasnost' [National Interests: Priorities and Security]. 2010, no. 15(72), pp. 34-43.

15. Kolomin E.V. (Ed.) Strakhovanie. Sovremennyy kurs [Insurance. Modern course: textbook]. Moscow, Finansy i statistika Publ., 2006.

Received 22 February 2018

\section{ОБРАЗЕЦ ЦИТИРОВАНИЯ}

Медяник, О.В. Лонгитюдное исследование отношения российских граждан к институтам страхования и инвестирования / О.В. Медяник // Вестник ЮУрГУ. Серия «Психология». - 2018. - Т. 11, № 2. C. 28-36. DOI: $10.14529 /$ psy180203

\section{FOR CITATION}

Medyanik O.V. Longitudinal Study of Attitude of Russian Citizens Toward Insurance and Investment Institutes. Bulletin of the South Ural State University. Ser. Psychology. 2018, vol. 11, no. 2, pp. 28-36. (in Russ.). DOI: $10.14529 /$ psy 180203 